\title{
SOBRE AS MUDANÇAS NO ENSINO MÉDIO: ALGUMAS (IN)CERTEZAS
}

\author{
ACERCA DE LOS CAMBIOS EN LA ESCUELA SECUNDARIA: ALGUNAS \\ CERTEZAS (IN)
}

\author{
ON THE (RECENT) CHANGES IN HIGH SCHOOL: BEYOND A HISTORICAL, \\ SOCIAL AND POLITICAL ANALYSIS
}

\author{
Shirlei de Souza CORREA ${ }^{1}$ \\ Verônica GESSER ${ }^{2}$
}

RESUMO: A descontinuidade das políticas públicas no EM é um fato e pode ser observado nas últimas duas ou três décadas, nos diferentes projetos lançados para esta etapa. Recentemente uma onda reformista vem propondo modificações no EM. Contudo, sabendo que as regras formais podem até direcionar as ações e orientar algumas propostas práticas, nos pautamos em Ball (1994) para afirmar que é a partir das regras informais que a política se adapta à realidade vivenciada. Partindo dessa premissa, consideramos que muitas são as incertezas a partir desta nova proposta para o EM, sobretudo a partir da estruturação curricular e da organização do ensino.

PALAVRAS-CHAVE: Ensino médio. Políticas públicas. Organização curricular.

RESUMEN: La discontinuidad de las políticas públicas en la EM es un hecho y se puede observar en las últimas dos o tres décadas, en los diferentes proyectos puestos en marcha para esta etapa. Recientemente una ola reformista ha estado proponiendo modificaciones en el EM. Sin embargo, sabiendo que las reglas formales pueden incluso dirigir acciones y guiar algunas propuestas prácticas, nos guiamos por Ball (1994) para afirmar que es a partir de las reglas informales que la política se adapta a la realidad experimentada. Sobre la base de esta premisa, consideramos que muchas incertidumbres se basan en esta nueva propuesta para el EM, especialmente desde la estructuración curricular y la organización de la enseñanza.

PALABRAS CLAVE: Escuela secundaria. Política pública. Organización curricular.

ABSTRACT: The discontinuity of public policies in the HS is a fact and can be observed in the last two or three decades, in the different projects launched for this stage. Recently another

${ }^{1}$ Universidade do Vale do Itajaí (UNIVALI), Itajaí - SC - Brasil. Doutorado em Educação, vinculado ao grupo de Políticas Públicas de Currículo e Avaliação. Mestrado em Educação pela mesma instituição. Pós-graduação pela UFSC. Dedico-me a pesquisas sobre questões curriculares: as teorias, as políticas públicas e os contextos práticos, com especial atenção aos movimentos que se constituem a partir da efetivação da formação humana integral. ORCID: https://orcid.org/0000-0001-9310-0454. E-mail: shirlei.correa@avantis.edu.br

${ }^{2}$ Universidade do Vale do Itajaí (UNIVALI), Itajaí - SC - Brasil. Professora e Vice Coordenadora do Programa de Pós-Graduação Stricto-Sensu em Educação (Mestrado e Doutorado). Pós-doutorado em Educação: Currículo e Ensino pela Barry University, Florida - USA (Financiamento: CAPES). Orcid: https://orcid.org/0000-0003-2170064X. E-mail: gesserv@univali.br

RPGE- Revista on line de Política e Gestão Educacional, Araraquara, v. 23, n. 3, p. 680-695, set./dez., 2019 ISSN: $1519-9029$ 
reformist wave has been proposing changes in HS. However, knowing that formal rules can direct actions and guide some practical proposals, we are guided by Ball (1994) to affirm that it is from the informal rules that politics adapts to the reality experienced. Starting from this premise, we consider that many are the uncertainties from this new proposal for the HS, especially from the curricular structuring and the organization of the teaching.

KEYWORDS: High school. Public policy. Curriculum organization.

\section{Introdução}

Há tempos em que o Ensino Médio - EM brasileiro tem servido de motivação para uma série de discussões, seja a partir da sua organização, seja a partir do seu funcionamento e, principalmente, a partir dos índices que denunciam o insucesso desta que é a última etapa da educação básica brasileira.

Contudo, nestes últimos meses, diante dos acontecimentos impactantes para o EM brasileiro, as discussões tem se acalorado, principalmente diante das transformações e modificações na estrutura e organização curricular. Tanto os movimentos em defesa, como aqueles que criticam estas mudanças nos permitem perceber a necessidade de discutir algumas questões que fazem parte deste movimento vivenciado pelo EM brasileiro.

Considerando estas questões, esse artigo foi organizado com o objetivo de discutir os diferentes movimentos que o EM brasileiro vivenciou, problematizando, a partir dessa trajetória, a questão central: as recentes mudanças. Para isso, exploramos inicialmente a (des)continuidade das políticas públicas voltadas ao EM, bem como algumas tentativas de romper a dualidade instaurada historicamente. Em seguida, discutimos o impacto destas modificações impostas inicialmente via Medida Provisória e as proposições destas mudanças no contexto educacional do EM brasileiro.

\section{As políticas públicas educacionais para o EM: alguns (des)caminhos}

Embora reconhecendo os importantes momentos pelos quais EM brasileiro (ainda com outra nomenclatura) passou, desde a conquista da escola laica, enfrentando a dualidade do ensino - entre o propedêutico e o profissional, optamos por acelerar nossa discussão e ter como palco as ações acontecidas a partir da década de 1980, sobretudo por entender esse período como fecundo para as mudanças mais impactantes no contexto educacional mundial. 
O cenário político e econômico vivenciado nos anos anteriores a este período, nos países pertencentes à América Latina, estava marcado por crises que denunciavam ${ }^{3}$ desde o aumento da inflação e do desemprego ao endividamento dos cofres públicos. Na tentativa de superar essa crise e discutir ações que pudessem elevar o crescimento destes países, uma reunião, conhecida mundialmente como "Consenso de Washington", foi realizada na capital americana. A proposta discutida neste encontro, que contava com a participação de economistas americanos e latinoamericanos, era a de garantir o desenvolvimento destes países em crise. Como resultado deste encontro, houve a criação de um documento com algumas orientações, entre elas, destacamos três propostas: 1. Privatização de empresas estatais; 2. Diminuição dos tributos para as empresas e; 3. Abertura comercial e econômica (DEMO, 1997).

Essas condições, ao serem aceitas por estes países, garantiram a disseminação do neoliberalismo e passaram a influenciar outros contextos que iam além da economia, entre eles, a educação. Sobretudo, por que as (poderosas e influentes) instituições como o Fundo Monetário Internacional - FMI e o Banco Mundial - BM se utilizavam das propostas tipicamente neoliberais como condição necessária para a concessão de novos empréstimos.

O contexto brasileiro, marcado pelas lutas políticas, econômicas e sociais e, estimuladas pelo anseio da sociedade civil pelo retorno à democracia, foi palco, neste período, de algumas reformas que deram uma nova configuração à sociedade brasileira. A Constituição Federal CF, de 1988 bem como a Lei de Diretrizes e Bases - LDB, de 1996, assumiam papel central no que tange a essas novas mudanças no cenário educacional do país, que, assim como em outros setores, foi diretamente modificada após o período ditatorial, sobretudo, com a chegada desses movimentos influenciados pelo Neoliberalismo.

A CF, símbolo da democratização do país, assumiu uma relação intencional com a educação, privilegiando o desenvolvimento global do educando, contrariando a fórmula Taylorista/Fordista que influenciava a educação até então orientada pelo regime ditatorial. Na sua redação, a educação era citada, no artigo 205 com o seguinte texto: “A educação, direito de todos e dever do Estado e da família, será promovida e incentivada com a colaboração da sociedade, visando o pleno desenvolvimento da pessoa, seu preparo para o exercício da cidadania e sua qualificação para o trabalho.”.

Do mesmo modo, a nova LDB de número 9394, aprovada em 1996, expressava, a partir de seu texto, características democráticas, o que marcou importantes mudanças, sobretudo, ao considerar a educação como bem público e de direito de todos os cidadãos. Contudo, em meio

${ }^{3}$ Recomendamos ler sobre a crise do Estado de Bem-Estar Social, Pedro Demo (1997). 
a contradições, esta mesma legislação imprimiu, na prática, um discurso neoliberal sobre a educação do país, que segundo Nascimento (2007), caracterizava-se pela flexibilização ao adequar-se aos padrões atuais de desregulamentação e privatização, atendendo também, aos interesses do governo. Esses interesses, que propiciavam à LDB uma função não somente de "indutora de mudanças, mas também como resultado do quadro de mudança" (MOEHLECKE, 2012, p. 56), voltavam-se, sobretudo, à necessidade de adequação que o país vivia, de vincularse à sociabilidade capitalista e garantir sua inserção na economia mundial. Esse processo de ajuste vivido pelo país neste período sofreu influências, também, dos organismos internacionais.

Utilizando o discurso de inserir o Brasil nessa nova ordem mundial, na lógica da globalização econômica internacional, o governo brasileiro, e de muitos outros países, acolheu a fórmula do Neoliberalismo como a solução imediata para os problemas recorrentes que o país vivenciava, optando por ações como a desregulamentação da economia, a mínima intervenção estatal, a privatização, a redução de impostos, o incentivo à competição e a obtenção de lucro.

Tendo a educação como um dos principais alvos, a hegemonia neoliberal manteve-se atrelada à ideia de que o Estado, ao aderir tal proposta, deixaria de manter estruturas burocráticas, desincumbindo-se das despesas, deixando para a iniciativa privada a promoção da educação de qualidade, visando a garantia da eficiência.

A partir das adaptações necessárias à intervenção do projeto neoliberalista, uma série de mudanças protagonizou uma nova concepção de educação. No caso do EM, a primeira referese à troca de nomenclatura: o antigo ensino de $2^{\circ}$ grau passou a ser denominado "Ensino Médio". Com nova denominação, o EM passou a ser considerado, a partir desta legislação, como etapa final da educação básica, assumindo sua função formativa. Além destas, a Lei no 9394/96 trouxe outra alteração: ao negar os dispositivos legais da Lei n 5.692/71, o parágrafo $2^{\circ}$ do Art. $1^{\circ}$ determina que a educação escolar e, consequentemente o EM, deve vincular-se ao mundo do trabalho e à prática social. O EM, a partir do Artigo 35 da referida lei, tinha a finalidade de garantir a

[...] consolidação e aprofundamento dos conhecimentos adquiridos no Ensino Fundamental, possibilitando o prosseguimento de estudos, a preparação básica para o trabalho e a cidadania do educando, para continuar aprendendo de modo a ser capaz de se adaptar com flexibilidade a novas condições de ocupação ou aperfeiçoamento posteriores; o aprimoramento do educando como pessoa humana, incluída a formação ética e o desenvolvimento da autonomia intelectual e do pensamento crítico; a compreensão dos fundamentos científico-tecnológicos dos processos produtivos, relacionando a teoria com a prática, no ensino de cada disciplina (BRASIL, 1996). 
As mudanças estabelecidas pela LDB logo foram acrescidas por outras que, na visão de Frigotto (2005), estavam estritamente embasadas por ações autoritárias e mercantilistas. Em 17 de abril de 1997, sob o governo Fernando Henrique Cardoso, o Decreto n. 2.208, deixou público o novo rumo que o EM tomaria, estando, a partir de então, o ensino técnico oferecido de forma complementar, paralela ou sequencial, obrigatoriamente, separado do EM regular. O Art. $5^{\circ}$ deste decreto apontava a principal mudança nessa modalidade de ensino: "A educação profissional de nível técnico terá organização curricular própria e independente do ensino médio". Dessa forma, ficava evidente a ruptura entre o processo que vinha se desenvolvendo, através de um currículo integrado entre educação profissional e EM. Na visão de Morais (2013, p. 22) essa nova configuração curricular, aliada às mudanças políticas, favoreceram a implantação e a racionalização econômica de base privada. O que resultou, conforme anunciado, na forte presença de organismos internacionais nas reformas, financiamento e organização da educação do EM no país.

Fica claro que o contexto político e econômico vivenciado neste período no Brasil foi influenciado pelas condições estabelecidas a partir da década de 1990, e, a partir daí, fazia-se necessária a reforma do Estado. Tal reorganização estatal - ocorrida em diversos países que mantinham relação de dependência com os países desenvolvidos, em especial os da América Latina, resultou na disponibilização de apoio técnico e financeiro por parte dos organismos internacionais. Na visão de Frigotto e Ciavatta (2006, p. 624), esses apoios, apesar de atenderam a necessidade de recursos financeiros que o Brasil vivenciava na época e, principalmente, promoverem a inserção do país na economia globalizada, contribuíram de forma negativa para a expansão do EM, sobretudo porque nestes princípios de cunho neoliberal "estava presente a visão produtivista, denominada de acumulação (ou teoria) de capital humano que concebe educação como preparação dos indivíduos para o mercado de trabalho".

O Art. $7^{\circ}$ do Decreto n. 2.208/1997, estabelece que, para a elaboração das diretrizes curriculares para o ensino técnico "deverão ser realizados estudos de identificação do perfil de competências necessárias às atividades requeridas, ouvidos os setores interessados, inclusive trabalhadores e empregadores". O que deixa claro, portanto, que a organização curricular, de acordo com essa intencionalidade, seguia um modelo de competências necessário à performance individual do desenvolvimento e estava a serviço da organicidade, flexibilidade e adequação às atividades produtivas.

No que tange a organização curricular, essa tendência foi influente, uma vez que hipertrofiou "a dimensão individualista e competição e induziram à formação aligeirada de RPGE- Revista on line de Política e Gestão Educacional, Araraquara, v. 23, n. 3, p. 680-695, set./dez., $2019 \quad$ ISSN: 1519-9029 DOI: $10.22633 /$ rpge.v23i3.12943 
jovens e adultos trabalhadores em cursos pragmáticos, tecnicistas e fragmentados ou, a treinamentos breves de preparação para o trabalho". O que se vivenciou a partir deste contexto foi uma adaptação do currículo para o atendimento das necessidades do mercado de trabalho, atendendo uma lógica econômica. Para Isleb (2014, p. 29):

Ressalta-se que tanto as DCNEM quanto os PCN's se constituíram como políticas curriculares centrais na década de 1990. Seus princípios estavam baseados no desenvolvimento de competências e habilidades, que atrelavam a formação dos sujeitos de maneira mais pragmática e estrita, voltada a atender às demandas do mundo do trabalho.

Embora estes documentos tenham sido alvo de críticas, uma vez que sua elaboração não envolveu a participação dos professores e não houve o debate popular, foram marcos neste contexto histórico e contribuíram para a organização da educação, sobretudo, no EM. Os Parâmetros Curriculares Nacionais - PCNs, definiram uma modificação na organização curricular, quando esse deixou de ser organizado por disciplinas e passou a ser organizado a partir de orientações que permitiam a formulação de perfis profissionais, baseado, como dito, no desenvolvimento das competências. Do mesmo modo, as Diretrizes Curriculares Nacionais do Ensino Médio - DCNEM, elaboradas no fim da década de 1990, moldaram-se a partir destas determinantes, a educação vivia a subordinação ao mercado. Moehlecke (2012) e Lopes (2006), contribuem: através do discurso híbrido das diretrizes, havia planos e ações tendenciosas e intencionais que se voltavam à educação como formadora de mão de obra, voltadas ao atendimento exclusivo das necessidades do mercado. Seguindo o mesmo tom, Czernisz afirma que havia um

[...] reforço à tendência de uma formação caracterizada por forte vinculação com os requisitos exigidos do trabalhador por um mercado norteado pelo avanço tecnológico. No ensino médio, esse dado é reforçado pelo inciso II do artigo 35 da LDBEN n. 9.394/96, que comenta a adaptação com flexibilidade às novas ocupações. É reforçado também pelo artigo 39 desta Lei ao se referir à formação que contempla o trabalho, a ciência e a tecnologia como forma de se vincular à vida produtiva (CZERNISZ, 2013, p. 264).

Diante deste "modelo", cabia às escolas a organização de objetivos próprios e diferenciados: de um lado as escolas de EM normal, com o currículo voltado a preparação para o ensino superior ou garantindo a simples terminalidade, enquanto, do outro lado, atuavam as escolas voltadas à profissionalização, com a responsabilidade em estabelecer seus próprios projetos curriculares, por habilitação ou área, por disciplinas ou módulos, respeitando o limite 
de 30\% da carga horária mínima obrigatória. Considerando, além destas, as características próprias da economia, do avanço tecnológico e da sociedade local.

Para Moehlecke (2012, p. 56), neste período muitos destes documentos foram "apresentados à comunidade escolar com o intuito de direcionar as mudanças tidas como necessárias nesse nível de ensino". Esses documentos, continua a autora, "tinham a intenção de propagar um discurso irreal, de que o EM era "para a vida", com a presença de um currículo centrado na formação geral”. Corroborando, Lopes (2006) afirma que a real intenção da reforma era de ampliar os índices de matrícula e garantir a formação de sujeitos com habilidades e competências, essenciais na vida e no trabalho.

Já no governo do presidente Luiz Inácio Lula da Silva, estas novas propostas estimularam a revogação do antigo decreto, resultando na criação do Decreto $n^{\circ} 5.154$, de 23 de julho de 2004, que passou a unificar o EM profissionalizante ao EM normal. O decreto apontou a perspectiva de formação integrada entre os conteúdos da educação geral e da formação profissional, o que, na visão dos idealistas, significaria o primeiro passo em direção a um projeto unitário de educação. Intrínseco a este movimento, surgia o projeto de formação humana integral, baseado, sobretudo, numa concepção curricular integrada, na tentativa de superar a dualidade histórica vivenciada pelo EM.

Essa nova legislação indicava, ainda, três formas de articulação entre a educação profissional técnica de nível médio e o ensino médio: a integrada, a concomitante e a subsequente. Para Costa (2013), essas políticas educacionais brasileiras criaram, nas últimas décadas, um contexto favorável à consolidação da matrícula na última etapa da educação básica em escolas públicas estaduais e,

Uma nova realidade da escola média: os trabalhadores passam a ter como principal alternativa uma formação não profissionalizante. O Decreto $\mathrm{n}^{\circ}$ 2.208/97 altera a proposta dual, com escola média de educação geral agora também para os que vivem do trabalho. O ensino médio não profissionalizante deixou de ser exclusividade da burguesia e a escola profissional somente para os trabalhadores (COSTA, 2013, p. 191).

Moehlecke (2012), ao fazer uma outra análise, afirma que a promessa que estava implícita nos documentos que tratavam do EM e tinham como tema a integração dos estudos, foi uma ação forjada de melhoria, pois continuava, ainda, em favor das condições neoliberalistas. A cargo dos sistemas e redes de ensino, essa integração entre os tipos de EM gerou algumas implicações que respondiam, como dito, ao contexto neoliberal instituído na década de 1990, instaurado no país e no mundo, resultando em parcerias com os setores 
privados, programas-piloto, e ainda a secundarização da educação em detrimento às exigências legais e mercadológicas.

Embora, como afirma esta autora, esse projeto não tivesse rompido com as concepções neoliberais (e diga-se que esse nem era seu principal objetivo), muito se progrediu a partir deste decreto. A questão referente ao financiamento, quando o EM passou a ser contemplado pelo Fundo Nacional de Financiamento da Educação Básica - FUNDEB, foi uma das importantes mudanças que serviu de base à uma série de outras ações que foram desencadeadas no decorrer dos anos seguintes. Entre eles, o Programa de integração da Educação Profissional com a Educação na modalidade de Jovens e Adultos; o Programa Brasil Profissionalizado, que incentiva a educação profissional nas escolas públicas; a instituição do Programa Ensino Médio Inovador e o incentivo às redes estaduais de educação de criação de iniciativas curriculares inovadoras entre outras, foram ações realizadas com o propósito de diversificar as oportunidades, considerando, sobretudo, a necessidade vivenciada na época de elevar as matrículas no EM.

Estas ações marcaram o início de um novo tempo para o EM brasileiro, que, embora servindo aos ideais neoliberais (LOPES, 2006; MOELECKE, 2012), passou a considerar o projeto de formação humana integral através da educação unitária, objetivando articular educação e trabalho ${ }^{4}$, como expresso nas novas DCNEM, que partiram desta concepção, tendo como tema central a questão curricular, para defender uma outra dinâmica a esta que é a última etapa da educação básica, buscando, através de diferentes formas de organização do currículo, a ressignificação dos saberes escolares para que fossem capazes de conferir qualidade e ampliar a permanência dos jovens na escola. A função do EM, segundo os documentos,

[...] vai além da formação profissional, atinge a construção da cidadania. É preciso oferecer a nossos jovens novas perspectivas culturais para que possam expandir seus horizontes e dotá-los de autonomia intelectual, assegurandolhes o acesso ao conhecimento historicamente acumulado e à produção coletiva de novos conhecimentos, sem perder de vista que a educação também é, em grande medida, uma chave para o exercício dos demais direitos sociais (DCNEM, 2010, p. 145).

\footnotetext{
${ }^{4}$ Embora não seja o caminho (metodológico) escolhido para essa discussão, é importe afirmar que, a partir desta articulação, muitas questões ganharam espaço e passaram a ser discutidas por estudiosos como Lopes (2006); Kuenzer (2002), que defendiam a ideia de que o Decreto de 2004 maximizou desafios da ordem política e pedagógica no cenário educacional do país, o que desencadeou problemáticas que tinham como questão a integração do currículo - seja na seleção dos conhecimentos, na organização destas propostas, nos escritos legais ou na prática desenrolada no cotidiano. Estas problemáticas partiam, sobretudo, do dilema histórico vivenciado pela escola: formar para a cidadania ou formar para o trabalho produtivo? E, a partir desta questão, a seguinte: como arquitetar uma proposta curricular que se mantenha fiel à perspectiva da formação integrada? RPGE- Revista on line de Política e Gestão Educacional, Araraquara, v. 23, n. 3, p. 680-695, set./dez., $2019 \quad$ ISSN: 1519-9029 DOI: $10.22633 /$ rpge.v23i3.12943 (c) BY-NC-SA
} 
Entretanto, essas ações, embora reconhecidas como um esforço na tentativa de dar outras características ao EM, não foram capazes de reverter o problema histórico vivenciado: os números apontam que, mesmo após estas novas promessas de um novo EM, aliada as ações propostas a partir de programas e ações educacionais que tinham como base a formação humana integral, a evolução não foi capaz de modificar os baixos e persistentes índices de permanência dos alunos no EM, denunciando, portanto, que há algo de errado, seja na estrutura, seja na organização do atual EM (GRIKE, 2016).

\section{As últimas mudanças: um novo EM(?)}

Reconhecendo esse cenário, em que o EM apresentava-se com baixos e persistentes índices, bem como a necessidade de modificá-lo, uma Comissão Especial destinada a promover estudos e proposições para a reformulação do EM - CEENSI, da Câmara dos Deputados, criou o Projeto de Lei - PL n ${ }^{\circ}$ 6840/2013 com a finalidade de propor mudanças para a estrutura do atual EM.

Desde então, os debates a respeito das ações de melhoria para esta, que é a última etapa da Educação de base brasileira, tem se acalorado. De um lado seus defensores, que propõe um EM modificado, sobretudo, na sua estrutura. Sob o argumento que o currículo atual é "ultrapassado, extremamente carregado, com excesso de conteúdo, formal, padronizado, com muitas disciplinas obrigatórias numa dinâmica que não reconhece as diferenças individuais e geográficas dos alunos", os relatores do projeto propõe alterações na Lei de Diretrizes e Bases da Educação Nacional - LDB para garantir a organização dos currículos do EM por áreas do conhecimento. Por outro lado, aqueles que criticam e negam as ações propostas pela Comissão, apresentadas na forma de PL nº 6840/2013.

Essas críticas geraram importantes movimentos contrários (SAVIANI, 2016) às ações propostas. Um dos mais importantes foi criado a partir reunião das principais entidades ligadas à Educação do país (ANPED - Associação Nacional de Pós-graduação e Pesquisa em Educação, a ANFOPE - Associação Nacional pela Formação dos Profissionais da Educação e a ANPAE - Associação Nacional de Política e Administração da educação) e resultou no grupo Movimento Nacional em Defesa do Ensino Médio, criado no início de 2014, no Paraná, representada por um grupo de especialistas da Universidade Federal deste estado. Esse grupo manifestou-se, em documento público, contrário à proposta:

[...] a proposição de opções formativas em ênfases de escolha dos estudantes reforça a fragmentação e hierarquia do conhecimento escolar que as DCNEM

RPGE- Revista on line de Política e Gestão Educacional, Araraquara, v. 23, n. 3, p. 680-695, set./dez., $2019 \quad$ ISSN: 1519-9029 DOI: $10.22633 /$ rpge.v23i3.12943 
lograram enfrentar. O PL no 6.840/2013 retoma o modelo curricular dos tempos da ditadura militar, de viés eficienticista e mercadológico. A organização com ênfases de escolha para uma ou outra área contraria tanto a Constituição Federal quanto a LDB que asseguram o desenvolvimento pleno do educando e a formação comum como direito.

Contudo, a aprovação da MP nº 746, no segundo semestre de 2016, ignorou essas ações e as discussões acontecidas em torno das propostas, o que intensificou ainda mais a onda de críticas. Outras manifestações foram realizadas: especialistas que discutem o EM e/ou as questões curriculares, como Silva e Krackvitz (2016), Saviani (2016), Frigotto (2016), expuseram sua opinião, contrariando as ações do novo governo ${ }^{5}$, enquanto os alunos protagonizavam momentos de protesto ao ocuparem as sedes das escolas, impedindo o funcionamento e a continuidade das aulas, apoiados, em algumas circunstâncias, pelos pais e professores.

As críticas em torno das mudanças no EM que tinham como alvo as modificações do currículo e o aumento do tempo de permanência dos alunos na escola tiveram continuidade e foram infladas em consequência deste movimento, autoritário e antidemocrático (SAVIANI, 2016). O Fórum Nacional de Educação, contrariando a ação, se pronunciou através de nota técnica:

Compreendemos que uma ampla e efetiva transformação no ensino médio e na educação brasileira não se dará no afogadilho e não pode ignorar movimentos que já tem propostas construídas para a melhoria do ensino médio e da educação como um todo. Não existe medida precipitada, apressada e ilegítima que seja capaz de garantir o direito à educação de qualidade aos(às) estudantes, razões pelas quais nossa posição é pela retirada da medida provisória e que a discussão seja encaminhada em outros termos e instrumentos, inclusive no congresso nacional, também pressionado e desrespeitado pelo açodamento do governo, que não se propôs garantir nem tempo nem espaço nem participação da sociedade civil para o debate qualificado e responsável que é requerido para o trato de matéria tão cara ao povo brasileiro, a saber, a educação de nossa juventude (BRASIL, 2016, p. 03)

Ao interromper as discussões propostas no PL nº 6840/2013 e impedir a participação da comunidade, como expresso pela nota do FNE, a MP trouxe uma série de mudanças para o EM brasileiro. A principal refere-se ao seu poder explícito, pois trata-se de um instrumento com força de lei, que quando adotado pelo presidente da República, em casos de relevância e

${ }^{5}$ A MP foi lançada num período de extrema instabilidade para o cenário político e econômico do país, depois do impeachment de Dilma Rousseff e a posse de Michel Temer.

RPGE- Revista on line de Política e Gestão Educacional, Araraquara, v. 23, n. 3, p. 680-695, set./dez., $2019 \quad$ ISSN: 1519-9029 
urgência, produz efeitos imediatos. E, como já anunciado, a MP cumpriu sua função legal e abriu caminho para a aprovação da Lei no 13415/2017.

Com a aprovação dessa Lei, as mudanças no EM, tanto na organização e funcionamento, desde a estruturação do currículo e a permanência dos alunos tem sido defendida pelo governo a partir da premissa de que esse atual modelo precisa ser alterado, ter reduzido o número de matérias obrigatórias e garantir aos estudantes a opção por diferentes formações, inclusive de natureza profissional ou técnica.

Partindo dessa premissa e colocando em prática o plano de mudanças para o EM, o MEC lançou um edital no final de 2016, com a finalidade de implementar, em algumas escolas estaduais, a nova proposta. Sob esse aspecto, consideramos as observações de Saviani (2016) e de Silva (2016). Para o primeiro autor, esse novo modelo serve de "vitrine", uma vez que tem, apenas, algumas escolas selecionadas para participar destas mudanças. Ao abordar a questão do investimento, o autor problematiza o fato da aprovação da PEC 241/2017 e a limitação de investimentos: que condições democráticas são essas, se serão beneficiadas algumas escolas em detrimentos a outras? Para a atora, esse modelo implementado pela Lei $\mathrm{n}^{\circ}$ 13415/2017, poderá trazer maior espaço de atuação e/ou parcerias dos setores privados, sobretudo na operacionalização dos itinerários formativos e na oferta da formação profissional - já que as condições de infraestrutura são precárias em algumas escolas brasileiras.

Contudo, diante dessa proposta, são muitas as críticas que compreendem estes itinerários formativos. Para Silva esse movimento abrirá precedentes para uma "forma indiscriminada e igualmente precária de formação técnico-profissional acentuada pela privatização por meio de parcerias" (SILVA, 2016, p. 7). O que levaria, para Saviani (2016), à um retrocesso aos tempos ditatoriais, quando a grande maioria dos jovens era afastada da educação superior e tomada pelo movimento de profissionalização generalizada. Instituindo, portanto, dois movimentos distintos para o (mesmo?) EM: um respondendo à demanda da formação de mão de obra - característica do neoliberalismo e suas consequências para a trajetória do EM (PINTO, 2002), e outro preparando para a "acessão" aos cursos superiores que seriam abarcados pelas escolas privadas como um negócio lucrativo - não muito diferente do que já assistimos.

Ao considerar esse conjunto de propostas na prática, nos pautamos em Ball (1994) e nos seus estudos sobre o ciclo de análise das políticas. Para o autor é a partir do texto escrito, que a política se constitui, sendo que "as respostas a esses textos têm consequências reais. Essas consequências são vivenciadas dentro do terceiro contexto, o contexto da prática" 
(MAINARDES, 2006, p. 53). Considerando que o texto propõe, porém, não domina a prática, entendemos que os leitores e/ou interpretadores não são neutros, eles estão encharcados de histórias, crenças, vontades, desejos e necessidades. Nas palavras deste autor, citado por Mainardes (2006, p. 53),

Políticas serão interpretadas diferentemente uma vez que histórias, experiências, valores, propósitos e interesses são diversos. A questão é que os autores dos textos políticos não podem controlar os significados de seus textos. Partes podem ser rejeitadas, selecionadas, ignoradas, deliberadamente mal-entendidas, réplicas podem ser superficiais etc. Além disso, interpretação é uma questão de disputa.

Em meio a esta discussão, tomando como foco o novo EM, essa é uma questão que, apesar de ter reconhecida sua possibilidade, não podemos, ainda, discutir. As ações e reações do texto escrito colocado em prática ainda são impossíveis de analisar, dada a prematuridade dos acontecimentos. O que sabemos, com base nas teorias de alguns autores, é que a organização curricular oficial, determinada legalmente, sofrerá interferências na prática. Já que o currículo formal ou oficial, determinado por uma decisão político-administrativa, está em poder dos professores que irão moldá-los e terão a decisão final na sua organização (LOPES, 2006; PACHECO, 2009). Já que, para este último autor, "toda política é dependente de regras formais e informais fortemente interiorizadas nos diversos níveis de decisão" (p. 67). Esta afirmação vem ao encontro no que se refere às políticas curriculares para o EM, que vem sofrendo modificações, respondendo a diversos interesses.

As regras formais podem até direcionar as ações e orientar algumas propostas práticas, contudo, é a partir das regras informais que a política se adapta à realidade vivenciada, se condiciona. Pois sabemos que as políticas expressam movimento e são entendidas longe de uma perspectiva linear e sistematizada, mas sim de uma voltada a diversidade e ao conflito - que tem íntima relação com o contexto da prática, vivenciado no cotidiano escolar.

\section{Considerações}

No caso do EM brasileiro muitos são os discursos, como temos visto nas discussões a respeito, que propõem a partir desse novo modelo mudanças significativas para reverter a atual situação. A necessidade de uma reforma - entendida num sentido amplo -, de modificação da estrutura educacional (YOUNG, 2007) é inquestionável, sobretudo se aceitarmos a premissa 
que essa "não é uma simples resposta de mudança, mas sim uma exigência do conjunto de reformas que pressionam a instituição escolar" (PACHECO, 2005, p. 149).

No caso brasileiro o clima reformista (SANTOS, 2007) vivenciado após a década de 1990 (embora marcado por episódios anteriores, principalmente como os movimentos do escolanovismo, no início do século passado) ganhou espaço no contexto educacional, sobretudo no âmbito do EM, tendo como referencial a nova LDB. Com as modificações em suas emendas, influenciadas por questões extra educacionais e refletindo diretamente da organização do currículo, os anúncios de novos rumos para o EM, ainda que marcados pelo insucesso, tornaram-se constantes. A partir destes anúncios, novas e diferentes condições foram aplicadas às discussões que tinham no currículo a centralidade das reformas. Sobretudo, quando o entendimento dado ao currículo, baseado em Pacheco (2009), é de um campo amplo de conhecimento, centrado no tempo e espaço, capaz de perpassar as relações de poder, estando centralizado nas políticas educacionais.

Essas novas mudanças no EM, vividas nestes últimos meses, podem (e tendem a isto) garantir uma reforma no cenário educacional brasileiro, imprimindo mudanças na estrutura e funcionamento e, especialmente aquelas voltadas ao currículo. Entretanto, não podemos ter a garantira que essas atingirão, de fato, a prática dos professores e a aprendizagem dos alunos. Uma vez que os professores são os decisores ou os adaptadores das políticas no contexto da prática. Contudo, cabe problematizar que nem o conceito de mudança, tampouco as ações tem, efetivamente, relação com melhoria. $\mathrm{O}$ abismo conceitual entre reforma curricular e inovação curricular, pode, dependendo do discurso, depositar no professor a responsabilidade de ser protagonista; aquele que na prática deve optar entre tornar sua práxis diferente ou responder às necessidades impostas legalmente. Assim, como afirma Canário (2003), ao professor cabe a decisão entre ser o executor das propostas ou o produtor de inovações.

Para tanto, diante deste contexto em que o atual EM brasileiro se encontra, temos na concepção de inovação uma incerteza. Pois, como afirma Goodson (2001, p. 31), a invenção no contexto da prática sem o apoio de grupos externos mais amplos não consegue imprimir novos padrões que venham a se tornar, ao longo do tempo, tradições curriculares. Para o autor, "a mudança fundamental exige a "invenção de (novas) tradições". Portanto, ao pensarmos nesse novo EM, sobretudo quando colocado em prática, podemos problematizar a necessidade de discutir, além das alterações organizacionais e normativas, as práticas curriculares desenvolvidas ao nível das escolas e das salas de aula - pois serão estas que determinarão e ajudarão a responder, para onde, de fato, caminha o (novo) EM brasileiro. 


\section{REFERÊNCIAS}

BALL, S. J. Educational reform: a critical and post-structural approach. Buckingham: Open University Press, 1994.

BOWE, R.; BALL, S.; GOLD, A. Reforming education \& changing schools: case studies in policy sociology. London: Routledge, 1992.

BRASIL. Constituição da República Federativa do Brasil de 1988. Brasília: Senado, 2006.

BRASIL. Congresso Nacional. Lei no 9.394, de 20 de dezembro de 1996. Estabelece as Diretrizes e Bases da Educação Nacional. Brasília, 1996. Disponível em:

http://www.planalto.gov.br/ccivil_03/leis/19394.htm. Acesso em: 15 jun. 2017.

BRASIL. Decreto no 2.208, de 17 de abril de 1997. Regulamenta o $\S 2^{\circ}$ do art. 36 e os arts. 39 a 42 da Lei $n^{\circ} 9.394$, de 20 de dezembro de 1996, que estabelece as diretrizes e bases da educação nacional. Disponível em: http://www.planalto.gov.br/ccivil_03/decreto/D2208.htm . Acesso em: 04 jan. 2018.

BRASIL. Decreto no 5.154, de 23 de julho de 2004. Regulamenta o $\S 2^{\circ}$ do art. 36 e os arts. 39 a 41 da Lei $\mathrm{n}^{\circ}$ 9.394, de 20 de dezembro de 1996, que estabelece as diretrizes e bases da educação nacional, e dá outras providências. Brasília, 1997. Disponível em:

http://www.planalto.gov.br/ccivil_03/_ato20042006/2004/decreto/d5154.htm. Acesso em: 15 jun. 2017.

BRASIL. Projeto de Lei no 6840 de 2013. Disponível em:

http://www.camara.gov.br/proposicoesWeb/fichadetramitacao?idProposicao=602570. Acesso em: 02 abr. 2018.

BRASIL. $45^{\text {a }}$ Nota Pública Sobre a Medida Provisória relativa ao ensino médio. Fórum Nacional de Educação. 2016. Disponível em

http://contee.org.br/contee/index.php/2016/09/fne-divulga-nota-contra-a-mp-do-ensinomedio/ Acesso em 13 fev. 2018.

BRASIL. Lei $\mathbf{n}^{\mathbf{0}}$ 13415, de 16 de fevereiro de 2017. Disponível

em: http://www.camara.gov.br/proposicoesWeb/fichadetramitacao?idProposicao=602570.

Acesso em: 30 mar. 2018.

CANÁRIO, R. O que é a Escola? Porto: Porto Editora, 2005.

CZERNISZ, E. C. S. As novas diretrizes para o ensino médio e os "antigos" desafios escolares. Roteiro, [S.1.], v. 38, n. 2, p. 257-272, jul. 2013. ISSN 2177-6059. Disponível em: http://editora.unoesc.edu.br/index.php/roteiro/article/view/2348. Acesso em: 01 jun. 2017.

COSTA. G. L. M. O ensino médio no Brasil: desafios à matrícula e ao trabalho docente. R. bras. Est. pedag., Brasília, v. 94, n. 236, p. 185-210, jan./abr. 2013. 
DEMO, P. Cidadania menor: algumas indicações quantitativas de nossa pobreza política. Petrópolis: Vozes, 1997.

FRIGOTTO, G. Possibilidades e desafio na organização do currículo integrado. In: FRIGOTTO, G.; CIAVATTA, M.; RAMOS, M. (orgs). Ensino Médio Integrado: concepção e contradições. São Paulo: Cortez, 2005.

FRIGOTTO, G. A reforma do Ensino Médio do (des)governo Temer. 2016. Disponível em http://www.anped.org.br/news/reforma-de-ensino-medio-do-des-governo-de-turno-decreta-seuma-escola-para-os-ricos-e-outra. Acesso 30 mar. 2017.

FRIGOTTO, G.; CIAVATTA, M. A formação do cidadão produtivo: a cultura de mercado no ensino médio técnico. Brasília. Instituto Nacional de Estudos e Pesquisas Educacionais Anísio Teixeira, 2006. Disponível em:

http://www.publicacoes.inep.gov.br/portal/download/434. Acesso em: 03 dez. 2017.

GOODSON, I. O currículo em mudança. Porto: Porto Editora, 2001.

GRIKE, F. Concepções de interdisciplinaridade: o programa ensino médio inovador. Dissertação (Mestrado em Educação.) - Universidade Federal do Paraná, Faculdade de Educação. Disponível em: http://repositorio.utfpr.edu.br/jspui/handle/1/1738. Acesso em 22 mar 2017.

ISLEB, V. O Programa Ensino Médio Inovador e sua relação com os dados de fluxo escolar. Dissertação (Mestrado em Educação.) - Universidade Federal do Paraná, Faculdade de Educação. 2014. 171 f. Disponível em http://www.observatoriodoensinomedio.ufpr.br/wpcontent/uploads/2014/04/Vivian-Isleb-disserta\%C3\%A7\%C3\%A3o-final-2014.pdf Acesso em 5 abr. 2018.

LOPES, A. C. Discursos nas políticas de currículo. Currículo sem Fronteiras, v. 6, n. 2, p. 33-52, julho/dezembro 2006.

MAINARDES, J. Abordagem do ciclo de políticas: uma contribuição para a análise de políticas educacionais. Educação e Sociedade. Campinas, v. 27, n. 94, p. 47-69, jan./abr. 2006.

MOEHLECKE, S. O ensino médio e as novas diretrizes curriculares nacionais: entre recorrências e novas inquietações. Revista Brasileira de Educação, Rio de Janeiro, v. 17, n. 49, p. 39-50, 2012.

MONTAÑO. C. E. O projeto neoliberal de resposta à "questão social" e a funcionalidade do “terceiro setor". Lutas Sociais (PUCSP), PUC - São Paulo, v. 8, p. 53-64, 2001.

MORAIS, L. P. As políticas públicas de economia solidária (ESOL): avanços e limites para a inserção sociolaboral dos grupos-problema. 2013. 263 p. Tese (Doutorado) Universidade Estadual de Campinas, Instituto de Economia, Campinas, SP. Disponível em: http://www.bibliotecadigital.unicamp.br/document/?code=000905687. Acesso em: 1 abr. 2018. 
NASCIMENTO, M. N. Ensino Médio no Brasil: determinações históricas. Publ. UEPG Ci. Hum., Ci. Soc. Apl., Ling., Letras e Artes, Ponta Grossa, 15 (1) 77-87, jun. 2007.

PACHECO, J. A. Políticas Curriculares: referencias para análise. Porto Alegre: Artmed, 2009.

PINTO, J. M. de R. O Ensino Médio. In: OLIVEIRA, Romualdo Portela; ADRIÃO, Theresa. (Org.). Organização do Ensino no Brasil. 1 ed. São Paulo: Xamã, p 51-76. 2002

SAVIANI, D. Palestra: A última do "Ensino Médio". Evento: Contrarreformas Neoliberais e os caminhos da Esquerda. Disponível em https://www.youtube.com/watch?v=TnpnRq21Iuc. Acesso em 15 fev. 2017.

SECRETARIA DE EDUCAÇÃO DE SANTA CATARINA. Princípios de uma educação integral. Uma parceria entre a Secretaria de Estado da Educação de Santa Catarina e o instituto Ayrton Senna. Caderno II, 2017. Disponível em www.sed.sc.gov.br Acesso em: 13 abr. 2017.

SILVA, M. R. Políticas educacionais para o Ensino Médio e sua gestão no Brasil contemporâneo. Entrevista. Dialogia, São Paulo, n. 23, p. 17-29, jan./jun. 2016. Disponível em http://www4.uninove.br/ojs/index.php/dialogia/article/viewFile/6504/3198. Acesso em: 30 mar. 2018.

SILVA, M. R.; KRAWCZYK, N. Pesquisadoras "conversam” com PL 6.840 de reforma do Ensino Médio. Carta Capital na Escola. Opinião. Edição de 21 de julho de 2015. Disponível em http://www.cartaeducacao.com.br/opiniao/pesquisadoras-conversam-com-pl6-840-dereforma-do-ensino-medio. Acesso em: 28 mar. 2018.

YOUNG, M. F. D. Bringing knowledge back in: from social constructivism to social realism in the sociology of education. London: Routledge, 2007.

\section{Como referenciar esse artigo:}

CORRÊA, Shirlei de Souza.; GESSER, Verônica. Sobre as mudanças no Ensino Médio: algumas (in)certezas. Revista on line de Política e Gestão Educacional, Araraquara, v. 23, n. 3, 680-695, set./dez., 2019. E-ISSN: 1519-9029. DOI: 10.22633/rpge.v23i3.12943

Data de Submissão: 06/04/2019

Revisões Requeridas: 10/05/2019

Aceite em: 05/06/2019

Publicado em: 15/08/2019 